\title{
Inventorying a Library Collection-One After Thirty Years, and One After Two Years
}

A Listen-and-Learn Session Presented by

Richard A. Lammert, Concordia Theological Seminary, Fort Wayne, Indiana

Stephen Sweeney, St. John Vianney Theological Seminary, Denver, Colorado

\begin{abstract}
Inventorying a library's collection is something that most libraries do at some time. This listen-and-learn session was designed to show the experience of two different libraries in conducting an inventory. The inventory in the first library was done for the first time in thirty years, because the physical collections of the library were finally in one place, permitting an inventory to be done fairly easily. The inventory in the second library was done for the fourth time in a biennial process. The process in these two libraries was presented so that attendees could determine what part of the methods presented might be applicable to their own situation.
\end{abstract}

\section{RICHARD LAMMERT, TECHNICAL SERVICES LIBRARIAN, WAYNE AND BARBARA KROEMER LIBRARY, CONCORDIA THEOLOGICAL SEMINARY}

Although I say in the title to this presentation that the inventory that I will document was the first one in thirty years, no one knows for sure when a previous inventory had been conducted. Concordia Theological Seminary moved from a campus in Springfield, Illinois, to a campus in Fort Wayne, Indiana, in 1976. This move affected the library, since its collections were in a 30,000-square-foot building in Springfield, which had to move into a 15,000-square-foot building in Fort Wayne. A portion of the collection (about 25,000 to 30,000 volumes) was placed in storage (located in various places around the campus during the time the items remained in storage). Only 
when an expansion and renovation of the library, started in 2009 and completed in 2015, had expanded the facility to 60,000 square feet could all holdings of the library be accommodated in one place.

The library's holdings underwent retrospective conversion in the 1980s. Smart barcodes were added to books in the early 2000 s. The library's machine-readable cataloging had migrated three times to different systems. But at no time was there a comparison between the item, its barcode, and the attached record. The integration of all parts of the collection under one roof allowed the library to address the pressing need of actually seeing how the physical items compared to the electronic representation.

There were some specific, known problems. There were "orphan" smart barcodes remaining in a binder, barcodes for which no matching physical item had been found. There were items that were long overdue, some of which had migrated from an earlier circulation system. Some items in the catalog were identified with a temporary barcode that had been input during initial work with the item, but for which no actual barcode had been included.

The professional staff prepared a working document in the summer of 2017, listing these goals for the inventory work: (1) Verify that WorldShare Management Services (WMS, the current ILS) represents as accurately as possible the holdings of Kroemer Library; (2) Verify that the call number listed in the catalog matches the call number on the book; (3) Verify that the barcode listed in the catalog matches the barcode in the book; (4) Verify that the author and title in the catalog correspond to the book. The end purpose of the inventory process was to make sure that the catalog accurately reflected what was on the shelf, and to take action on all books not on the shelf.

The library's collection development policy provided the basis for determining the disposition of books that were not on the shelf (or were on the shelf, but needed repair). Factors considered when looking at whether to replace or repair a book included the number of libraries from which the book was available, the availability of full text online, the number of circulations the library copy had, and whether the book fit the definition of a "core" collection of a Lutheran seminary.

Goals need to drive the method used to achieve them. Most integrated library systems-including OCLC's WMS-have an 
inventorying capability, but these capabilities did not do everything we wanted. We used readily available (and free) tools to create the lists we needed for the inventory: MARC data from OCLC, MarcEdit to translate MARC data to a textual form, the perl scripting language to manipulate the textual data, a perl module (Library::CallNumber::LC) to sort call numbers, and Google sheets to store the shared, working copy of the inventory lists. We used these tools to create a spreadsheet that included all the elements we wanted to verify: barcode, call number, author, and title. (An attendee pointed out that OCLC reports could produce a listing of all these items, so we may have been incorrect in thinking that OCLC could not provide our lists.)

Three of the library's professional librarians prototyped the process in late summer 2017. The prototyping showed us that the process was one that student employees could easily manage. The prototyping also allowed us to put together an initial list of problems that might be encountered during the process, together with the steps for resolution.

The inventorying project was sizeable: the circulating collection of 139,752 volumes needed to be inventoried at the same time that the library was in use, so that volumes would go out and come in, some having been inventoried, while others not. An estimate of the length of the project was made by taking this total number of volumes, determining the average number of books handled in an hour, how many hours of student workers we could dedicate to the project, and which times of the year there would not be sufficient student workers available to dedicate any time to the project. Our estimate was that the project could be completed in approximately five and a half quarters. Thus, starting in the fall quarter of 2017 , we should be finished by the end of the spring quarter 2019 (an estimate that proved remarkably accurate).

The prototyping phase helped us determine a number of factors. One was the amount of time one person could reasonably spend doing the work (one half-hour). One was a realization that the person working did not have to compare the entire thirteen-digit barcode, but needed only to match the last four digits; the inventory sheet was modified to include only these four digits. Other than this, the inventory sheet was remarkably stable. The division of labor between student workers and librarians was shifted slightly after several months of work. The librarians had been checking on books not on the shelf to deter- 
mine if they were checked out. This step was given to one of the last student workers in the day to accomplish. This required another small change in the worksheet: the entire barcode was not on the sheet (it was included in the Google sheet used by the librarians), so that was added to expedite lookups by the student worker.

As already implied, student workers and professional librarians were involved in the project. The student workers did the physical inventory, marking books that were not on the shelf and pulling books that had some problem with them. The three professional librarians (on a rotating basis) went through the result of each previous day's work, acting on cases that needed resolution, and recording the activity and decisions in the Google sheet.

Close attention was paid to keep the project on track. A check was done each month to see whether the project was progressing on schedule, and whether it would be finished by the estimated completion date. The full professional staff reviewed the progress every week during their normal staff meeting. About twice a month the three professional librarians and the director met to review specific items that an individual librarian could not resolve.

Necessary adjustments were made as the need arose. As noted above, only a few changes were needed. The goals of the project had been clarified; the methods to achieve those goals had been developed and tested. There was consistent and continual overview of the project, to determine that adequate progress was being made and that any problems could be quickly and efficiently solved.

The outcome? We completed the project in the projected time, even having time to inventory the reference section before the end of Spring Quarter, 2019, the projected ending date of the project. We updated our holdings in WorldCat to reflect as accurately as possible our actual holdings throughout the project. During the course of the project, we handled or researched 5.5\% (7,683 items) of the circulating collection. It is worth noting that not all of these were "problem" children. Because our student workers were checking author and title, the librarians often had to review a book that was entered under a uniform title which wasn't on the book, or under a form of the author's name that wasn't on the book. These were necessary distractions, since we wanted to verify that the catalog listing was accurate, and they were quickly marked "OK” on our Google sheet and returned to the shelf. 
Statistics are interesting, but tell only a part of the story-but it is a part of the story. We withdrew 1,081 items during the process. Most of these items were ones that had not been on the shelf for decades, so this, for the most part, represented only a correction in our list of holdings. Almost 600 items were relabeled, and almost 700 had the local holding record updated. Some of the mistakes would generally not have made the item invisible: lack of a date in the call number, or the last digit of the cutter incorrect. However, some mistakes completely lost the item in the stacks: an incorrect classification number or even the wrong shelving location. So those 1300 items represent books that can now be found, when they might have been invisible earlier.

What would we have done differently? Actually, very little. We had defined our goal, or methods, and knew how long the project should take. That analysis required us to determine how we would handle books that weren't on the shelf because they were checked out, or otherwise unavailable. All of these steps had been done at the outset of the project. What was left were the problems of which we were unaware, problems that cropped up while we worked-but these were taken care of quickly because of the close oversight of the project.

What is next? There are several sections of the library's collections that we have yet to inventory. There is the determination of the disposition of books that were discovered not to be on the shelf during the inventory (these are what we call the "new missing" ones, in contrast to the ones we already knew were missing). Then there is the planning for a new periodic inventory-which will probably happen before another thirty years.

\section{STEPHEN SWEENEY, DIRECTOR, CARDINAL STAFFORD LIBRARY, ST. JOHN VIANNEY THEOLOGICAL SEMINARY}

In a 2017 issue of Collaborative Librarianship, Jennifer Harveland states one of the outcomes of inventory is that "[l]ibrary staff gained knowledge of the local collection during the process, and having organized it, were able to provide stronger customer service" (https://digitalcommons.du.edu/collaborativelibrarianship/). First, an introduction of Saint John Vianney Seminary followed by the inventory process that has happened over the past decade.

Saint John Vianney Theological Seminary (SJV) is the Catholic 
seminary in Denver with 3.5 FTE in the library. We serve a population of about 120 FTE seminarians and approximately thirty faculty and staff. Our seminarian/student population is $100 \%$ residential, and all students have the occasion to use the library. Saint John Vianney offers one nondegree program in the form of a propadeutic year (it's named the Spirituality Year). The seminary offers two philosophical degrees: a BA in Philosophy in affiliation with Regis University in Denver, and a BPhil degree in affiliation with the Angelicum in Rome. SJV offers to some students the opportunity to complete their philosophical studies by a nondegree "standard program" of coursework in philosophy. Two degree programs are offered in theology: the MDiv program is approved and accredited by ATS, and the STB (Baccalaureate Degree in Sacred Theology) is offered via affiliation with the Angelicum in Rome.

The library currently owns approximately 165,000 items and subscribes to OCLC WorldShare Management Services (WMS). The conversation first began in 2010 with the appointment of a new Library Director. In conversations with current staff and volunteers, the realization was arrived at that inventory (if it had occurred) had not happened since prior to 1978. It was at that point that one of the library's volunteers first began her employment at SJV. Frequent inventories use staff and financial resources and require community support and cooperation. Frequent inventories remind the users that we are responsible for this collection and that use of the collection has a real impact (negative and positive). Inventory also requires buy-in from the Academic Dean and the Rector-President, as we close access to the stacks for the duration of inventory of that part of the collection. We share some of the inventory statistics with our seminary community. The value of inventory lasts long after the process ends. It provides an opportunity for a look at the collection in a way that does not happen every day. Inventory gives us a chance to pay attention to the physical collections that do not circulate often or at all. Inventory tells part of the library story. It tells the story of the numbers of items we have and do not have, the areas that need attention (replacement, repair, correction, movement [shifting]), and areas of growth or decline.

SJV started its retrospective conversion in 2000. That project came to completion in 2010 , so the timing was right to begin inventory in 
2012. Over time, the number of missing items discovered in the inventory process has declined. In 2012, the missing volumes totaled more than 1,000. In 2015, this list dropped to 257. By 2017, that had dropped again to 206. And at the time of this presentation in 2019, the number of missing items hovered around 157.

Thinking still about the inventory process, SJV has always begun with the smaller parts of the collection a few weeks or months before the regular stacks. Over past inventory projects, approximately 20,000 items are scanned per week in the stacks. This is semi-dependent on staff allocated to the project. In 2012, we combined inventory with cleaning shelves and identifying books for repair. Two people shelf read as the books were replaced after cleaning. Eleven volunteers and three seminarians assisted in the cleaning. The cataloger was responsible for repair and corrections as problematic items were found. In 2017, SJV underwent a migration to WorldShare Management Systems. WMS was implemented after nearly twenty years of SirsiDynix. It was a slightly different process. In Sirsi, the scanner stored the bar codes and reports were run differently. The library has replaced or withdrawn items following each inventory. This allows the Library to accurately reflect on the shelf what is in our catalog and vice versa.

Among other reasons, a completed inventory is important for insurance purposes. The collection is a moving target, because even as inventory is happening, new items are being added to the collection. New items will be counted during the next inventory cycle. 